\title{
Domiciliary comparison of terbutaline treatment by metered dose inhaler with and without conical spacer in severe and moderately severe chronic asthma
}

\author{
J F O'REILLY, G GOULD, A H KENDRICK, G LASZLO \\ From the Respiratory Department, Bristol Royal Infirmary, Bristol
}

ABSTRACT The bronchodilator response to cumulative doses of terbutaline administered by metered dose inhaler with and without a conical spacer device and by Acorn nebuliser has been compared in groups of patients with chronic severe and moderately severe asthma. After laboratory studies the patients undertook a randomised domiciliary crossover comparison of bronchodilator response to terbutaline given by metered dose inhaler with and without a spacer device, during which the severity of asthma was assessed by thrice daily recordings of peak expiratory flow (PEF) and symptom score. Improvement in $\mathrm{FEV}_{1}$ produced in the laboratory by the metered dose inhaler with spacer device was significantly greater than by metered dose inhaler alone $(p<0.001)$ and similar to that from the nebuliser in both asthmatic groups throughout a range of terbutaline doses. In the domiciliary comparison mean midday and evening PEF rates were significantly higher with the use of the spacer device both in those with severe $(\mathrm{p}<0.01)$ and in those with moderately severe $(\mathrm{p}<$ $0.05)$ asthma, and mean morning PEF was significantly higher in the severe group $(\mathrm{p}<0.05)$. The spacer device also produced a significant improvement in symptom score in both the severe and the moderately severe groups $(\mathrm{p}<0.05)$. Regular domiciliary use of the spacer device with the metered dose inhaler improves bronchodilator response, particularly in patients with chronic severe asthma, and may be a useful alternative to nebuliser treatment.

Patients with severe asthma may fail to respond to bronchodilator drugs from a metered dose inhaler because of poor coordination or inability to inhale an adequate volume of air to carry the metered dose to the lungs in a single breath. ${ }^{1}$ This delivery system favours deposition of the drug in the oropharynx and large airways because of the high velocity of the propelled drug particles and the large size of the propellant droplets in which they are encased. ${ }^{2}$ Response to bronchodilators delivered from a nebuliser is frequently greater than response to bronchodilators from a metered dose inhaler, but this may simply reflect the larger doses of bronchodilator usually prescribed, as comparative studies with equivalent doses have shown similar bronchodilator responses in chronic, moderate, and acute severe asthma ${ }^{3-5}$ and whole lung deposition is similar in normal subjects with the two techniques. ${ }^{6} 7$ Further, the nebuliser does

Address for reprint requests: Dr JF O'Reilly, Department of Respiratory Medicine, Victoria Hospital, Blackpool FY3 8NR.

Accepted 22 April 1986 not require coordination of aerosol activation and inhalation, which is known to be poor in a large proportion of patients. ${ }^{2}$

Attempts have been made to improve lung deposition from a metered dose inhaler by insertion of a spacer between the inhaler and the mouth. A $22 \mathrm{~cm}$ conical spacer device with a metered dose inhaler has 옥 been shown to be as effective as a nebuliser in acute $\frac{D}{O}$ severe asthma, ${ }^{8}$ and more effective in laboratory studies of patients with chronic moderately severe $\widetilde{N}$ asthma. ${ }^{34}$ This may reflect greater lung deposition, ${ }^{9} \mathrm{~N}$ possibly in more peripheral airways. ${ }^{10}$ The role of the ${ }_{N}$ spacer device in the bronchodilator treatment of $\omega$ patients with chronic severe asthma, especially in regular domiciliary use, is unclear; but it is these patients $\stackrel{\varrho}{\subset}$ who are likely to be considered for treatment with a spacer device. This study was designed to compare ? responses of asthmatic patients to regular domiciliary bronchodilator treatment from a metered dose inhaler $\underset{\mathbb{D}}{\mathrm{D}}$ with and without a spacer device, and to give separate $\frac{?}{\mathbb{Q}}$ consideration to those with severe disease and those $\unrhd$ with only moderately severe chronic airflow obstruction. Bronchodilator responsiveness was character- 8 
ised by a series of dose-response curves obtained in the laboratory with the use of these devices and a jet nebuliser.

\section{Methods}

\section{PATIENTS}

We studied 10 patients with severe chronic asthma $\left(\mathrm{FEV}_{1}\right.$ less than 1.5 litres) and 10 patients with moderately severe chronic asthma $\left(\mathrm{FEV}_{1}>1.51\right)$, who gave informed consent. All were using regular inhaled bronchodilators from a metered dose inhaler. Bronchodilators were discontinued for at least 12 hours on the laboratory study days. Other drugs remained unchanged throughout the laboratory and domiciliary studies.

\section{LABORATORY PROTOCOL}

Patients attended the laboratory on three days and baseline assessments were made of radial pulse rate while they were sitting and of FEV 1 and forced vital capacity (FVC), the highest of three recordings on a rolling seal dry spirometer (Ohio) being taken for analysis. These measurements were repeated 20 minutes after each of four cumulative doubling doses of terbutaline $(0.5 \mathrm{mg}+1.0 \mathrm{mg}+2.0 \mathrm{mg}+4.0 \mathrm{mg})$ given at 30 minute intervals by nebuliser, metered dose inhaler and metered dose inhaler with spacer device in random order on different days. Patients were thus given a total cumulative dose of $7.5 \mathrm{mg}$ terbutaline by each technique.

The Acorn nebuliser was driven by compressed air at a flow rate of $71 \mathrm{~min}^{-1}$ and the appropriate dose of terbutaline respirator solution $(10 \mathrm{mg} / \mathrm{ml})$ diluted to $2 \mathrm{ml}$ with isotonic saline. Metered dose inhalers were specially prepared to release $0.5 \mathrm{mg}$ terbutaline per dose so that doses in the range commonly used in nebuliser treatment could be given without administration of excessive freon propellant. Patients were asked to inhale an appropriate number of doses using a standard technique. The conical spacer device studied was the Nebuhaler (Astra Pharmaceuticals). When using the spacer device with metered dose inhaler patients were instructed to take two deep inhalations after releasing the metered dose, with a breathhold of at least five seconds after the first inhalation.

\section{DOMICILIARY PROTOCOL}

The patients went on to undertake a randomised crossover comparison of bronchodilator response to terbutaline given by metered dose inhaler with and without a spacer device, each for two weeks. They were asked to take $1.0 \mathrm{mg}$ terbutaline three times daily by inhaling four consecutive doses from a standard terbutaline metered dose inhaler $(0.25 \mathrm{mg}$ per dose), using the technique previously described, and not to take additional doses. The best of three recordings of peak expiratory flow (PEF) was noted before each terbutaline treatment, a Wright mini peak flow meter being used. They recorded the symptomatic severity of asthma by means of a linear numerical symptom score, indicating a number from a linear scale from 1 ("absent") to 10 ("extremely severe").

\section{STATISTICAL ANALYSIS}

In the laboratory study the mean percentage bronchodilator responses obtained with each technique were compared by the Wilcoxon signed rank test, and mean slopes of regression lines for each dose-response curve by one way analysis of variance. In the domiciliary study the mean value of PEF and symptom scores at each time of day were averaged for each week. Values obtained using metered dose inhaler with and without spacer device were compared by the Wilcoxon signed rank test.

\section{Results}

\section{LABORATORY STUDY}

The mean $\mathrm{FEV}_{1}$ for the group with severe asthma was 0.951 (range $0.55-1.451$ ) and for those with moderately severe asthma $2 \cdot 201(1 \cdot 58-3 \cdot 221)$. Details for each patient are given in the table. There was no significant difference in mean baseline values of $F E V_{1}$ and FVC on the three study days in either group of asthmatic patients. Heart rate increased only slightly, there being no significant difference in mean, maximum, or incremental heart rates after terbutaline inhalation for any of the techniques in either group of patients.

\section{Severe asthma}

In the group with severe asthma the mean percentage $\mathrm{FEV}_{1}$ response to the initial dose of terbutaline $(0.5 \mathrm{mg})$ was significantly less with the metered dose inhaler $(13.5 \%)$ than with either the metered dose inhaler with spacer device $(22.3 \% ; p<0.01)$ or the nebuliser $(24.4 \% ; p<0.05)$. The dose-response curve for the metered dose inhaler was significantly displaced to the right of those for the inhaler with spacer device $(p<0.05)$ and the nebuliser $(p<0.01)$.

The mean percentage FVC response to terbutaline $0.5 \mathrm{mg}$ was significantly less with the metered dose inhaler $(10.5 \%)$ than with the nebuliser $(21.5 \%$; $p<$ 0.01 ), with an intermediate response with the inhaler with spacer device $(16.4 \%)$. At higher doses no significant difference was found between techniques.

\section{Moderately severe asthma}

In the moderately severe group of patients the mean percentage $\mathrm{FEV}_{1}$ response to terbutaline $0.5 \mathrm{mg}$ was again significantly less with the metered dose inhaler 
Baseline FEV ${ }_{1}$ and forced vital capacity (FVC) in 10 patients with severe and 10 with moderately severe chronic asthma

\begin{tabular}{|c|c|c|c|c|}
\hline Patient No & Age $(y)$ & Sex & FEV $V_{1}(l)(\%$ pred $)$ & $F V C(l)(\%$ pred $)$ \\
\hline \multicolumn{5}{|c|}{ Severe asthma } \\
\hline 1 & 68 & $\mathrm{~F}$ & $0.55(28.4)$ & $1.63 \quad(69 \cdot 4)$ \\
\hline 2 & 64 & $\mathbf{M}$ & $0.67(24.5)$ & $2.25 \quad(58 \cdot 4)$ \\
\hline 3 & 32 & $\mathrm{~F}$ & $0 \cdot 79(25 \cdot 1)$ & $1.68 \quad(43 \cdot 1)$ \\
\hline 4 & 56 & $\mathrm{~F}$ & $0.93(41 \cdot 3)$ & $2 \cdot 17 \quad(74 \cdot 8)$ \\
\hline 5 & 54 & $\mathrm{~F}$ & $0.97(42 \cdot 2)$ & $2 \cdot 1 \quad(67 \cdot 7)$ \\
\hline 6 & 44 & $\mathbf{M}$ & $0.98(27 \cdot 1)$ & $1 \cdot 7 \quad(36 \cdot 2)$ \\
\hline 7 & 56 & M & $1.00(34 \cdot 7)$ & $2 \cdot 42 \quad(61 \cdot 7)$ \\
\hline 8 & 59 & $\mathbf{M}$ & $1.07(36.9)$ & $2.53 \quad(64.0)$ \\
\hline 9 & 62 & $\mathbf{M}$ & $1 \cdot 11(38 \cdot 1)$ & $2 \cdot 38 \quad(56 \cdot 7)$ \\
\hline 10 & 40 & $\mathrm{~F}$ & $1.45(48 \cdot 3)$ & $2.55 \quad(68.0)$ \\
\hline Mean (SD) & \multicolumn{2}{|l|}{$53 \cdot 5(11 \cdot 4)$} & $0.95(0.25)(34 \cdot 7(8 \cdot 1))$ & $2 \cdot 14(0 \cdot 35)(60 \cdot 0(12 \cdot 1)$ \\
\hline \multicolumn{5}{|c|}{ Moderately severe asthma } \\
\hline 11 & 58 & M & $1 \cdot 58(51 \cdot 5)$ & $3.43 \quad(83 \cdot 7)$ \\
\hline 12 & 52 & M & $1.62(47.9)$ & $2.97 \quad(66 \cdot 0)$ \\
\hline $\begin{array}{l}13 \\
14\end{array}$ & $\begin{array}{l}32 \\
36\end{array}$ & $\begin{array}{l}F \\
F\end{array}$ & $\begin{array}{l}1.80(66.7) \\
1.83(61.2)\end{array}$ & $\begin{array}{ll}3.43 & (90.3) \\
3.77 & (99.2)\end{array}$ \\
\hline $\begin{array}{l}14 \\
15\end{array}$ & 62 & $\mathbf{M}$ & $\begin{array}{l}1 \cdot 83(61 \cdot 2) \\
1.88(65 \cdot 0)\end{array}$ & $\begin{array}{ll}3.77 & (99.2) \\
3.77 & (94 \cdot 2)\end{array}$ \\
\hline 16 & 44 & $\mathrm{~F}$ & $2 \cdot 1 \quad(73 \cdot 2)$ & $3.35 \quad(89.6)$ \\
\hline 17 & 39 & $\mathrm{M}$ & $2 \cdot 57(68 \cdot 5)$ & $4.13 \quad(86.9)$ \\
\hline 18 & 42 & M & $2 \cdot 67(70 \cdot 3)$ & $4.99(101.4)$ \\
\hline 19 & 37 & M & $2.78(82.9)$ & $4 \cdot 67(107 \cdot 3)$ \\
\hline 20 & 19 & $\mathrm{~F}$ & $3 \cdot 22(89 \cdot 2)$ & $4.23 \quad(93.0)$ \\
\hline Mean (SD) & \multicolumn{2}{|l|}{$42 \cdot 1(12 \cdot 7)$} & $2 \cdot 20(0 \cdot 56)(67 \cdot 6(12 \cdot 6))$ & $3.87(0.62)(91 \cdot 2(11 \cdot 3))$ \\
\hline
\end{tabular}

$\%$ pred-percentage of predicted normal value.

$(9 \cdot 2 \%)$ than with the inhaler with spacer device $(17.5 \% ; p<0.01)$. An intermediate response was obtained from the nebuliser $(12.6 \%)$. The doseresponse curves for the metered dose inhaler and nebuliser were significantly displaced to the right of that from for the inhaler with spacer device $(p<0.01)$.

Mean percentage FVC responses were not significantly different for any of the three techniques at any dose of terbutaline.

\section{DOMICILIARY STUDY}

Measurements of PEF

Mean baseline PEF values were examined and found to be closely similar for patients entering each limb of the crossover study. During the second week of treatment mean PEF was significantly higher for metered dose inhaler with spacer device than for metered dose inhaler alone in both groups of patients (figs 1 and 2). Use of the spacer device produced significantly higher peak flow rates throughout the day in the severely affected group $(p<0.05)$. In those with moderate asthma the improvement was significant only for the midday and evening readings $(p<0.05)$. Mean midday PEF was $15 \%$ higher in the severe group and $11 \%$ higher in the moderately severe group when the metered dose inhaler with a spacer device was used for two weeks than when the metered dose inhaler was used alone.

\section{Subjective assessment}

The mean baseline symptom score was closely similar for patients entering the two limbs of the crossover study. There was no significant difference in score $\frac{\circ}{\Phi}$ during the first week of treatment given by metered

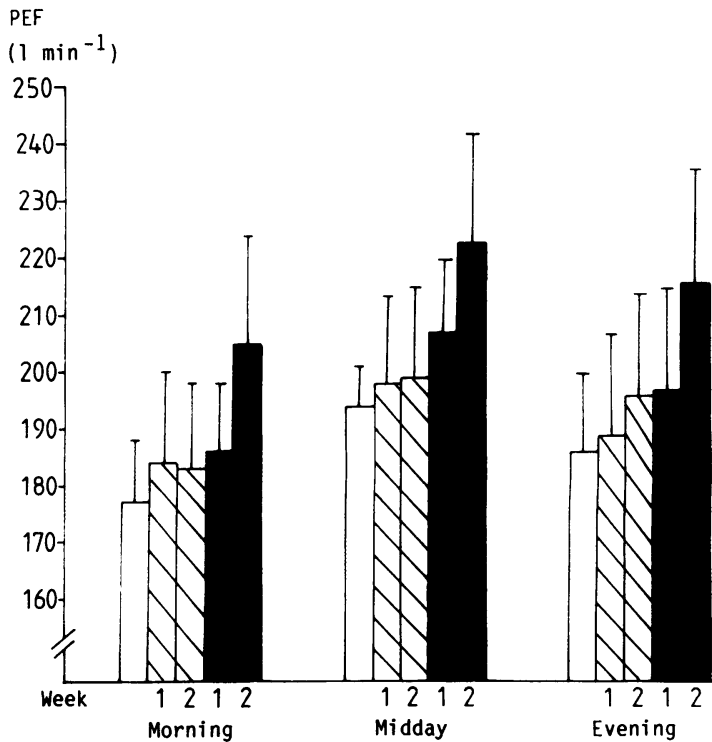

Fig 1 Baseline (open column) and average weekly peak expiratory flow (PEF) (mean and standard error) during terbutaline treatment by metered dose inhaler alone (hatched columns) and with spacer device (filled columns) in 10 patients with severe chronic asthma. 


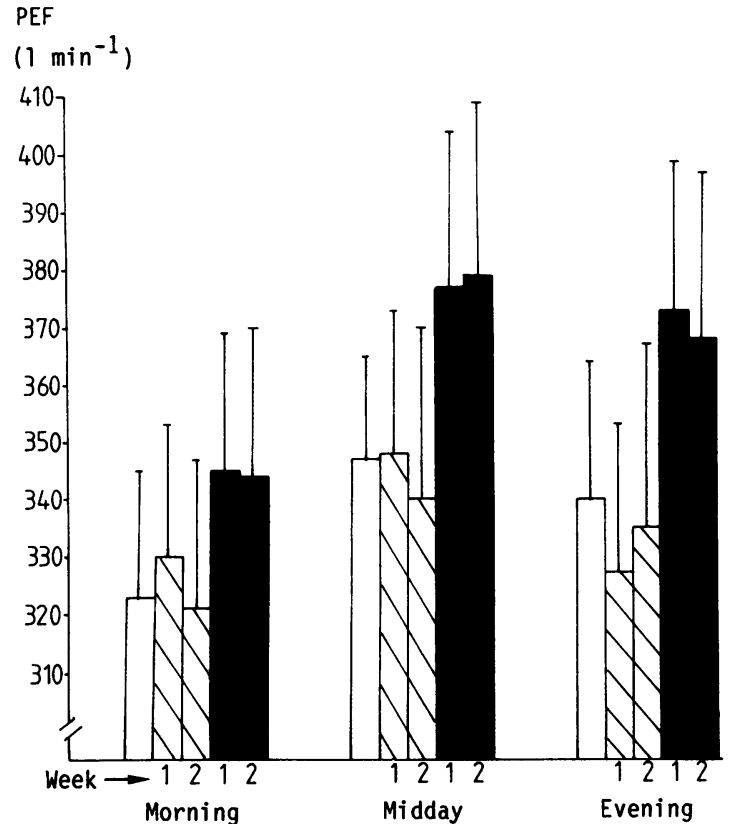

Fig 2 Baseline (open column) and average weekly peak expiratory flow (PEF) (mean and standard error) during terbutaline treatment by metered dose inhaler alone (hatched columns) and with spacer device (filled columns) in 10 patients with moderately severe chronic asthma.

dose inhaler or metered dose inhaler with spacer device in either severely or moderately severely affected patients at any time of day (figs 3 and 4). During the second week of treatment there were small but significant differences in mean symptom score in favour of the spacer device in the severe group throughout the day $(\mathrm{p}<0.05)$ and in the moderately severe group for the morning and evening observations $(\mathrm{p}<0.05)$.

\section{Discussion}

The conical shape of the spacer device used in the study was designed to envelope the aerosol cloud leaving the metered dose inhaler and thereby reduce drug deposition within the device: ${ }^{11}$ The length of the device allows deceleration of drug particles leaving the inhaler and has been shown to reduce oropharyngeal impaction while improving lung deposition. ${ }^{9}$ The device also allows reduction in the size of aerosol particles before inhalation by evaporation of propellant coating, enabling a cloud of slowly moving drug particles to be inhaled in a large volume, theoretically favouring peripheral lung deposition. ${ }^{12}$ Our study confirms the advantage of using the spacer device in patients with moderately severe chronic asthma as others have reported. ${ }^{34}$ It also demon-

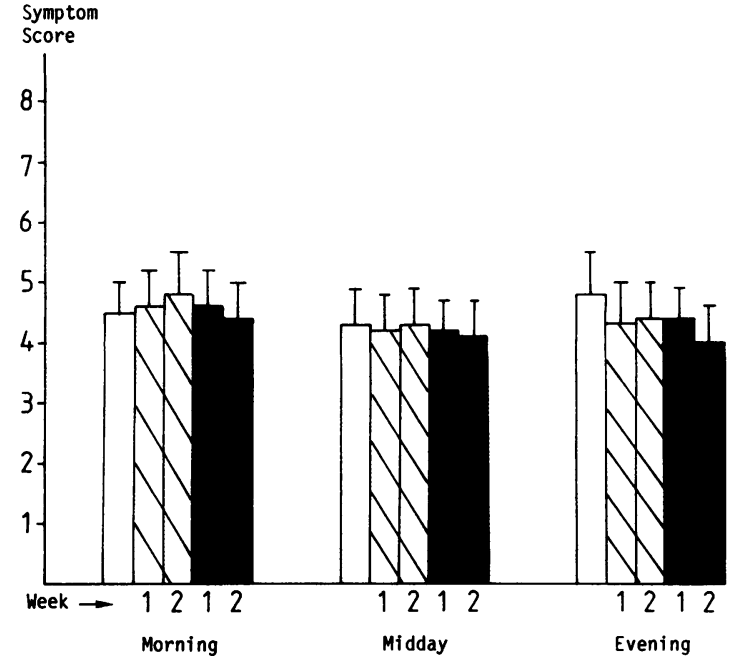

Fig 3 Baseline (open column) and average weekly symptom scores (mean and standard error) during terbutaline treatment by metered dose inhaler alone (hatched columns) and with spacer device (filled columns) in 10 patients with severe chronic asthma.

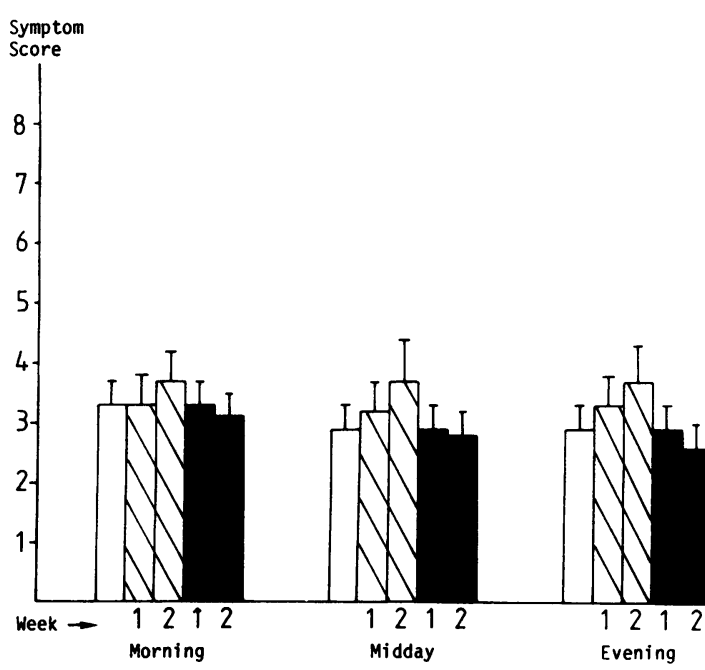

Fig 4 Baseline (open column) and average weekly symptom scores (mean and standard error) during terbutaline treatment by metered dose inhaler alone (hatched columns) and with spacer device (filled columns) in 10 patients with moderately severe chronic asthma.

strates for the first time a similar advantage in patients with severe chronic asthma. In both groups use of the spacer device doubled the mean improvement in FEV $_{1}$ obtained from a standard therapeutic dose of terbutaline given by metered dose inhaler alone. This is in keeping with the finding of Newman et al that the lung deposition of radiolabelled Teflon particles in the lung was doubled by use of a spacer device with a 
metered dose inhaler. ${ }^{913}$ The method of inhalation when this device is used removes the need for precise coordination of actuation of the metered dose inhaler and inhalation, which is known to be inadequate in many patients with asthma and which may partly explain the relatively poor performance of the metered dose inhaler used alone.

In the laboratory study we found no significant differences between bronchodilator responses to the use of metered dose inhaler with spacer device and of nebuliser in either group of patients, although, like others, ${ }^{34}$ we found a shift of the dose-response curve to the left in favour of use of the device by patients with moderately severe asthma; this is consistent with greater deposition of drug in the lung. This again is in keeping with evidence from radiolabelled aerosol deposition studies that the spacer device produces greater lung deposition than a jet nebuliser.

In the domiciliary study there was a statistically significant, though clinically undramatic, advantage in favour of use of the spacer device in both groups of asthmatic patients; this was seen by both in PEF recordings and in subjective assessments. Except for midday PEF in the moderately severe group, the advantages of using the spacer device did not appear until the second week of treatment, suggesting a cumulative benefit, particularly in the group with severe asthma. The improvement in mean morning PEF, measured before administration of the drug, in the severe group indicates a useful reduction in morning dip in PEF during use of the spacer device for a prolonged period. This was accompanied by an equivalent improvement in mean symptom score and may be of particular clinical value in these patients.

Improvement in symptoms of asthma and PEF during use of the spacer device with the metered dose inhaler is most unlikely to be due to placebo bias as no subjective or objective preference was observed during the first week of treatment. A double blind, double dummy study would be required to confirm this but would have required the inhalation of possibly unacceptable volumes of freon propellant.

We thank Astra Pharmaceuticals for supplying Nebu- halers and terbutaline canisters and Mrs E James for $\overrightarrow{\overline{\vec{p}}}$ typing the manuscript.

\section{References}

1 Newman S, Pavia D, Clarke S. How should a pressurized$\beta$-adrenergic bronchodilator be inhaled? Eur J Respir. Dis 1981;62:3-21.

2 Newman S, Pavia D, Moren F, Sheahan N, Clarke S ${ }^{\omega}$ Deposition of pressurized aerosol in the human respi $\overrightarrow{\times}$ ratory tract. Thorax 1981;36:52-5.

3 Cushley MJ, Lewin RA, Tattersfield AE. Comparison of three techniques of inhalation on airway response to terbutaline. Thorax 1983;38:108-13.

4 Morris J, Milledge JS, Moszoro H, Higgins A. Thळ efficiency of drug delivery by a pear-shaped spacer and metered-dose inhaler. Br J Dis Chest 1984;78:383-7.

5 Cayton RM, Webber B, Paterson JB, Clarke TJH. A comparison of salbutamol given by pressure-packed? aerosol or nebulisation via IPPB in acute asthma. $B r: \vec{P}$ Dis Chest 1978;72:222-5.

6 Lewis RA, Fleming JS, Balachandran W, Tattersfield AE. Particle size distribution and deposition from a jebo nebuliser; influence of humidity and temperature [abstract]. Clin Sci 1981;62:5P.

7 Walker SR, Evans ME, Richards AJ, Paterson JW. The clinical pharmacology of oral and inhaled salbutamol Clin Pharmacol Ther 1972;13:861-7.

8 Morgan MDL, Singh B, Frame MF, Williams SJ. Terō butaline aerosol given through a pear spacer in acute severe asthma. Br Med J 1982;285:849-50.

9 Newman SP, Moren F, Pavia D, Little F, Clarke SW Deposition of pressurized suspension aerosols inhaled through extension devices. Am Rev Respir Dis 198 124:317-20.

10 O'Reilly JF, Buchanan DK, Sudlow MF. Pressurized aerosol with conical spacer is an effective alternative tQ nebuliser in chronic stable asthma. $\mathrm{Br} \mathrm{Med}$ 1983;286:1548

11 Moren F. Drug deposition of pressurized inhalation aerosols. 1. Influence of activation tube design. Int Pharmaceut 1978;1:205-12.

12 Pavia D, Thompson ML. Aerosol inhalation and depth of deposition in the human lung AFCh. Environ Healt $\$$ 1977;34:131-7.

13 Newman SP. Aerosol deposition and in the lung. PhDT thesis, University of London, 1983. 